\title{
Analisis Kesiapan Peserta Didik SMANegeri 8 Padang Menghadapi Revolusi Industri 4.0.
}

\author{
Relsas Yogica, Sa'diatul Fuadiyah, Jihan Hasanah \\ Jurusan Biologi, FMIPA Universitas Negeri Padang \\ relsasyo@fmipa.unp.ac.id
}

\begin{abstract}
Industrial Revolution 4.0. is a time when human life is very dependent on the information base. This forces everyone to be ready, and have global competitiveness. The trick is to adapt information technology effectively. All aspects of life are affected, including formal education in high school. Here, the teacher plays an important role. Carry out learning with the orientation towards proficient technology, and wisely use technology. However, the implementation of the learning certainly requires basic thinking, how much ability students have. There are no data that reveal the readiness of students in secondary schools to face the Industrial Revolution 4.0, including in SMA Negeri 8 Padang. Thus, we conducted this descriptive study. We used a questionnaire, JRZ-IR4.0, to collect data from 603 students. Then, the data is analyzed and concludes the students' readiness. The results showed that the level of student readiness was quite ready, with an average of 3.18 and 3.15 points. These results form the basis for considering the direction of the learning process.
\end{abstract}

Keywords :Readiness, Student, 4.0.

This is an open access article distributed under the Creative Commons 4.0 Attribution License, which permits unrestricted use, distribution, and reproduction in any medium, provided the original work is properly cited. $@ 2019$ by author and Universitas Negeri Padang.

\section{PENDAHULUAN}

Karakteristik utama dari masa Revolusi Industri 4.0 adalah perkembangan pesat pada teknologi terbarukan, seperti big data, kecerdasan artifisial, tekonologi robot, dan teknologi nano.Big data merupakan representasi masa baru dari penggunaan dan eksplorasi data (Zikopoulos \& Eaton, 2011), yang saat ini telah mengekspansi setiap bidang ilmu pengetahuan dan teknik (Wu, Zhu, Wu, \& Ding, 2013). Kecerdasan artifisial merupakan faktor kunci untuk menggerakkan teknologi robotik (Lie \& Harjanto, 2018).

Perkembangan seperti ini tidak mungkin tidak mempengaruhi seluruh aspek nyata kehidupan, seperti sosial, ekonomi, kebudayaan, dan pendidikan. Aspek pendidikan merupakan salah satu aspek penting kehidupan yang berupaya untuk memanusiakan manusia(Syafril \& Zen, 2019).

Aspek pendidikan memiliki komponen setidaknya dalam lingkup formal pada jenjang dasar sampai ke jenjang yang lebih tinggi. Pada setiap jenjang ini, guru sangat berperan penting untuk menjadikan peserta didik memiliki kecakapan saat mereka lulus. Guru berperan untuk membimbing dan mengayomi peserta didik untuk membentuk suatu kecakapan tertentu (Palunga \& Marzuki, 2017). Kecakapan tersebut tentu saja berlandaskan pada kondisi terkini kehidupan masyarakat. Saat ini, kecakapan untuk menghadapi Revolusi Indusri 4.0. sangat dibutuhkan, misalnya adalah kreativitas yang tinggi (Wurianto, 2019).

Kecakapan pada masa Revolusi Industri 4.0. bukanlah sesuatu yang perlu dicemaskan. Hal ini disebabkan karena kecakapan dapat dipersiapkan sejak awal. Jika pihak yang dituntut untuk cakap tersebut dapat memahami makna dan kegunaannya. Di sekolah, guru dan peserta didik harus paham tentang kecakapan ini.

Guru dan peserta didik adalah faktor kunci keberhasilan pembelajaran di sekolah, termasuk pada tingkat sekolah menengah. Peran penting guru ini menjadi seorang guru sebagai muara untuk setiap perubahan dan inovasi pendidikan (Darmadi, 2016). Guru juga memiliki peran untuk memberdayakan setiap peserta didik dengan fasilitas yang ada dalam belajar, guna meningkatkan kualitas pembelajaran. Sementara itu, peserta didik juga memiliki tanggung jawab untuk belajar dengan baik, berusaha sekuat tenaga agar capaian pembelajaran tercapai dengan baik. Peserta didik harus memiliki motivasi untuk belajar (Matteucci, 2016), dengan memanfaatkan fasilitas yang ada.

Guru di masa Revolusi Industri 4.0., diharapkan menjadi guru yang cerdas, kreatif, 
terus berkarya, dan mengabdi sebagai pendidik. Selain itu, guru harus memiliki kualitas dan kuantitas. Guru di masa Revolusi Industri 4.0. seharusnya mampu menggunakan dan mengelola teknologi, serta mampu menciptakan efisiensi proses pembelajaran (Abdelrazeq, Janssen, Tummel, Richert, \& Jeschke, 2016). Oleh karena itu, guru harus mampu untuk mengarahkan proses pembelajaran pada arah kecakapan di masa Revolusi Industri 4.0.

Guru harus mempersiapkan perencanaan pembelajaran agar arahnya sesuai dengan tuntutan zaman. Rencana pelaksanaan proses pembelajaran yang baik menjelaskan tentang tujuan yang akan dicapai oleh peserta didik (Sweet, 2019). Perencanaan tersebut juga berlandaskan pada kebutuhan, dan kemampuan peserta didik. Sehingga nantinya perencanaan yang dibuat tidak sia-sia.

Penyusunan rencana pelaksanaan pembelajaran membutuhkan analisis yang mendalam, menimbang setiap kemungkinan dan potensi dari semua sumber daya. Kemampuan penyusunan rencana pembelajaran ini menjadi salah satu penilaian kinerja guru (Lestari, 2016). Perencanaan pembelajaran dengan basis kecapakan masa Revolusi Industri 4.0., dibutuhkan salah satunya informasi tentang sejauh mana kesiapan peserta didik untuk menghadapinya.

Berdasarkan hasil wawancara dengan wakil kepala sekolah, SMA Negeri 8 Padang telah bersiap untuk melaksanakan pembelajaran 4.0. Namun, guru kurang memahami tentang hal tersebut. Dampaknya, peserta didik tidak tahu tentang pendidikan 4.0. Hal ini disebabkan karena kurangnya informasi tentang kesiapan peserta didik, sehingga guru tidak mengetahui hendak memulai dari mana untuk mengajar.

Berdasarkan uraian tersebut maka Peneliti telah melaksanakan penelitian tentang kesiapan peserta didik di SMA Negeri 8 Padang menghadapi masa Revolusi Industri 4.0. Rumusan masalah penelitian adalah bagaimana tingkat kesiapan peserta didik menghadapi masa Revolusi Industri 4.0 dengan menggunakan angket JRZ.IR4.0. Angket ini dikembangkan sendiri oleh Tim Peneliti.

\section{METODE PENELITIAN}

Penelitian ini adalah penelitian deskriptif, yang bertujuan untuk mengetahui tingkat kesiapan peserta didik SMAN 8 Padang. Kami menggunakan anget JRZ.IR4.0, yang Peneliti kembangkan sendiri sebelum penelitian dimulai. Tingkat kesiapan peserta didik diukur dengan skala Likert yang telah dimodifikasi dan disesuaikan dengan kebutuhan penelitian Peneliti, yaitu nilai 5 (selalu), 4 (sering), 3 (kadang-kadang), 2 (jarang), dan 1 (tidak pernah). Deskripsi data Peneliti batasi pada tingkat kesiapan, tanpa menganalisis bagaimana dan mengapa hal tersebut dapat terjadi. Keterangan lengkap dapat dilihat pada Tabel 1.

Tabel 1. Kriteria Penilaian Hasil Pengukuran Angket JRZ-IR4.0.

\begin{tabular}{cc}
\hline Skor & Keterangan \\
\hline 1 & Tidak pernah \\
\hline 2 & Jarang \\
\hline 3 & Kadang-kadang \\
\hline 4 & Sering \\
\hline 5 & Selalu \\
\hline
\end{tabular}

Pengambilan data dengan menggunakan instrumen yang berupa kuesioner. Kuesioner adalah seperangkat pertanyaan tertulis untuk mendapatkan data dari pribadi seseorang atau segala sesuatu sesuai dengan kebutuhan penelitian (Arikunto, 2010). Kuesioner yang Peneliti gunakan adalah angket JRZ-IR4.0. Angket ini adalah angket tertutup. Angket tertutup adalah suatu angket yang menyediakan jawaban untuk dapat dipilih oleh responden (Nugroho, 2018).

Angket ini dikembangkan berdasarkan pada kecakapan abad 21, dengan menggunakan desain pengembangan Plomp. Dalam proses pengembangan, Peneliti meminta bantuan dari pakar pendidikan di Universitas Negeri Padang sebagai bahan pertimbangan perbaikan dan penyempurnaan angket, yakni Prof. Dr. Lufri, M.S. dan Prof. Dr. Ahmad Fauzan, M.Pd. M.Sc., selain itu Peneliti juga meminta bantuan dari berbagai pihak sekolah sebagai praktisi pendidikan.

Tahap penelitian Peneliti bagi menjadi 3 bagian, yakni tahap persiapan, tahap pelaksanaan dan tahap penyelesaian. Pada tahap-tahap tersebut, terdapat tahap pengembangan angket dan tahap pengukuran kesiapan menggunakan angket tersebut. Penelitian Peneliti lakukan pada rentang waktu Januari-Juni 2019 di Universitas Negeri Padang dan SMA Negeri 8 Padang dengan total sampel 603 orang peserta didik. 


\section{HASIL DAN PEMBAHASAN}

\section{A.}

Hasil

Berdasarkan penelitian yang telah Penelitilaksanakan, telah diketahui tingkat kesiapan peserta didik menghadapi masa Revolusi Industri 4.0. berdasarkan angket yang telah Peneliti kembangkan. Tabulasi data hasil penelitian berdasarkan indikator pengukuran dapat dilihat pada Tabel 2, dan tabulasi data hasil penelitian berdasarkan kelas dapat dilihat pada Tabel 3.

Tabel 2. Tabulasi Hasil Penelitian Berdasarkan Indikator Pengukuran

\begin{tabular}{ccc}
\hline Indikator & Nilai & Kriteria \\
\hline Critical Thinking & 2,93 & Cukup siap \\
\hline Creative & 3,13 & Cukup siap \\
\hline Collaboration & 2,99 & Cukup siap \\
\hline Communication & 3,23 & Cukup siap \\
\hline Commitment & 3,02 & Cukup siap \\
\hline Information & 3,47 & Siap \\
\hline Media Literacy & 2,93 & Cukup siap \\
\hline ICT Literacy & 2,82 & Cukup siap \\
\hline $\begin{array}{c}\text { Flexibility and } \\
\text { Adaptability }\end{array}$ & 3,26 & Siap \\
\hline $\begin{array}{c}\text { Initiative and Self- } \\
\text { Direction }\end{array}$ & 3,26 & Siap \\
\hline $\begin{array}{c}\text { Social and Cross- } \\
\text { Cultural }\end{array}$ & 3,19 & Cukup siap \\
\hline $\begin{array}{c}\text { Productivity and } \\
\text { Accountability }\end{array}$ & 3,10 & Cukup siap \\
\hline $\begin{array}{c}\text { Leadership and } \\
\text { Responsibility }\end{array}$ & 3,95 & Siap \\
\hline Rata-rata & 3,18 & Cukup siap \\
\hline
\end{tabular}

Tabel 3. Tabulasi Hasil Penelitian Berdasarkan Tingkatan Kelas

\begin{tabular}{ccc}
\hline Kelas & Nilai & Kriteria \\
\hline $\mathrm{X}$ & 3,16 & Cukup siap \\
\hline XI & 3,13 & Cukup siap \\
\hline Rata-rata & 3,15 & Cukup siap \\
\hline
\end{tabular}

\section{B. Pembahasan}

Kesiapan adalah suatu kondisi psikis seseorang. Kesiapan peserta didik berhubungan dengan kemampuan dan pemahaman mereka (Tomlinson, 2001). Hasil penelitian Peneliti menunjukkan hanya 2 kategori kesiapan peserta didik, yakni cukup siap dan siap. Kata "siap" menurut Kamus Besar Bahasa Indonesia online adalah sesuatu yang sudah bersedia untuk melakukan kegiatan. Kata "cukup siap" berarti sudah cukup bersedia untuk melakukan kegiatan, namun tidak lebih siap dibandingkan dengan kata "siap".

\section{Critical Thinking Skill}

Tingkat kesiapan peserta didik pada indikatorindikator ini adalah 2.93, dengan kategori cukup siap. Peserta didik dengan nilai ini adalah peserta didik yang cukup mampu untuk berpikiran kritis saat menyelidiki, menemukan kesalahan pada materi pembelajaran, memiliki dugaan dengan kata yang sulit, mampu membedakan fakta dan opini, mampu menjawab pertanyaan yang diberikan sesuai fakta, menjelaskan alasan yang jelas terhadap pertanyaan yang diberikan, menyelesaikan permasalahan, mencari solusi, menemukan informasi, mencari tahu suatu hal yang belum diketahui, menjawab permasalahan, menunjukan kebenaran pendapat.

Critical thinking adalah kemampuan seseorang untuk dirinya sendiri, mendisiplinkan dirinya, memonitor dirinya dan mampu berpikir untuk mengoreksi dirinya sendiri. Peserta didik yang memiliki kemampuan berpikir kritis dapat mengambil keputusan dengan data yang valid dan tidak diragukan (Holmes, Wieman, \& Bonn, 2015). Kemampuan berpikir kritis sudah dapat dipahami dengan baik di beberapa negara, namun belum dapat dimengerti mengapa kemampuan ini perlu ditanamkan (Huber \& Kuncel, 2016).

\section{Creative Skill}

Nilai rata-rata kesiapan peserta didik pada indikator creative skill adalah 3.13, dengan kategori cukup siap. Peserta didik yang memiliki kemampuan ini adalah individu yang cukup mampu melakukan hal yang kreatif dengan menciptakan karya baru, mencoba membuat suatu produk, spontan menjawab pertanyaan, dan lain-lain.

Kreativitas adalah suatu bentuk kemampuan seseorang untuk melakukan hal baru. Kreativitas seseorang terkait erat dengan pengetahuan yang diperolehnya (Zioga, Harrison, Pearce, Bhattacharya, \& Luft, 2019). Kreativitas dapat dibentuk dan dipengaruhi oleh faktor lingkungan yang menjadi bahan tiru (So \& $\mathrm{Hu}, 2019)$, dan penilaian guru terhadap kreativitas peserta didik tersebut (Gralewski \& Karwowski, 2019).

\section{Collaboration Skill}


Tingkat kesiapan peserta didik pada indikatorcolaboration skilladalah 2.99, dengan kategori cukup siap. Pada skill ini peserta didik cukup mampu bekerja sama dengan kelompok/orang lain dengan menyebarluaskan informasi, membuat kelompok belajar, mengajak teman untuk menyepakati argumen, berinteraksi, dan lain-lain.

Kemampuan kolaborasi peserta didik adalah kemampuan untuk melakukan usaha pencapaian tujuan bersama antara peserta didik dengan peserta didik yang lain. Namun, sesuai dengan perkembangan interaksi peserta didik di sekolah, mereka tidak hanya berinteraksi dengan teman sebaya, namun juga dengan guru dan perangkat sekolah lainnya. Kemampuan kolaborasi peserta didik dengan guru dalam kelas dapat mengubah suasana pembelajaran menjadi lebih baik (Magen-Nagar, Shachar, \& Argaman, 2019), misalnya dengan menggunakan metode blended learning (Laisema, 2018).

\section{Communication Skill}

Tingkat kesiapan peserta didik pada indikator communication skilladalah 3.23, dengan kategori cukup siap. Peserta didik cukup mampuberkomunikasi dengan baik,misalnya saat berinteraksi dengan teman sebaya, orang lain yang lebih muda, orang lain yang lebih tua, dan lain-lain.

Kemampuan berkomunikasi dengan baik sangat penting dimiliki oleh peserta didik. Bahkan, kemampuan komunikasi yang baik adalah syarat untuk menjadi pemimpin yang baik (Zentner, 2016). Kemampuan komunikasi dalam pembelajaran dapat dilatih dengan menggunakan model pembelajaran inkuiri (Lewa, Susanto, \& Marwoto, 2018), model pembelajaran brain based learning(Nilawati, Duskri, \& Sari, 2019), pendekatan konstruktivistik (Harahap \&Harahap, 2018), pendekatan kontekstual (Sugandi \& Bernard, 2018), dan lain sebagainya.

\section{Commitment Skill}

Tingkat kesiapan peserta didik pada indikatorcommitmentskill adalah 3.02, dengan kategori cukup siap. Peserta didik cukup mampu untuk memiliki pendirian dalam pengucapan maupun tindakan dengan cara memanfaatkan waktu, membatasi waktu, berusaha dalam mempelajari hal-hal baru, bertekat untuk terus belajar, dan lain-lain.
Komitmen peserta didik adalah nilai konsistensi peserta didik untuk melakukan tindakan yang dianggapnya benar dengan mempertimbangkan kebaikan-kebaikan orang lain. Banyak hal yang dapat dilakukan oleh guru untuk mempertahankan komitmen baik peserta didik, antara lain dengan pelatihan goal setting(Hidayatullah \& Zwagery, 2018), penguatan sikap komitmen (Anggraini, 2019), mediasi konsep diri akademik (Mardhiyah \& Indianti, 2018), dan lain sebagainya.

\section{Information Skill}

Tingkat kesiapan peserta didik pada indikator information skilladalah 3.46, dengan kategori siap. Peserta didik telah siap untuk menggunakan, membedakan jenis, mengenali, menemukan, dan menyimpulkan informasi dari sumber terpercaya.

Literasi informasi peserta didik berkaitan dengan kemampuan mereka untuk menemukan dan mengolah informasi dari berbagai sumber.Literasi informasi peserta didik berhubungan positif signifikan dengan prestasi belajar mereka (Murti \& Winoto, 2018). Kemampuan literasi informasi peserta didik di sekolah sangatlah bergantung pada kemampuan sekolah untuk menyediakan informasi dengan benar. Beberapa upaya yang dapat dilakukan adalah dengan membuat library class (Ningsih, 2018), dan membentuk Gerakan Literasi Sekolah (Fauziah \& Lestari, 2018).

\section{Media Literacy Skill}

Tingkat kesiapan peserta didik pada indikator media literacy skilladalah 2.93, dengan kategori cukup siap. Peserta didik cukup mampu menggunakan media dengan memahami gambar yang dilihat, suara yang didenga, mampu membuat pesan dan menyampaikan informasi melalui gambar, rekaman, foto video, dan lainlain.

Literasi media pada diri peserta didik merupakan jenis kemampuan untuk mengenali media dan informasi yang dibawa media tersebut apakah pantas dan tidak pantas bagi mereka. Bagi peserta didik, kompetensi pribadi (kemampuan teknis, pemahaman kritis, dan kemampuan komunikasi) mempengaruhi kemampuan literasi media mereka (Zelfiah, 2018).

\section{ICT Literacy Skill}

Tingkat kesiapan ICT literacy skilladalah 2.82, dengan cukup siap. Peserta didik cukum 
mampu memahami penggunaan komputer, telepon genggam, internet sebagai sumber informasi, mampu mengelompokan data yang ada dalam komputer, menyimpan informasi dari internet,mampu membuat bahan presentasi dalam komputer, mampu memanfaatkan layanan surat elektronik,dan sejenisnya.

Mahir menggunakan ICTmerupakan suatu bentuk kemampuan yang sangat dibutuhkan saat ini. Bagi peserta didik, kemampuan menggunakan ICT dapat meningkatkan keyakinan diri untuk sukses, dan aspirasi belajar (Siddiq, Gochyyev, \& Wilson, 2017). Meskipun ada perbedaan yang tidak signifikan kemampuan peserta didik laki-laki dan perempuan dalam menguasai ICT (Siddiq \& Scherer, 2019), guru selayaknya konsisten menerapkan dan mengembangkan kemampuan tersebut, dengan cara menanamkan kebiasaan (Ahn \& Chae, 2016).

\section{Flexibility and Adaptability Skill}

Kemampuan peserta didik pada indikator ini adalah 3.26, dengan kategorisiap. Maknanya adalah, peserta didik sudah mampu untuk peka terhadap perubahan sekitar, mudah berinteraksi dengan mengetahui perubahan lingkungan sekitarnya, perubahan sikap orang lain, mampu memulai percakapan dengan orang lain bahkan dengan orang lain yang baru dikenal, mudah mengakrabkan diri dengan orang yang baru dikenal, menyesuaikan diri, menerima perubahan yang ada di lingkungan selagi tidak merugikan diri sendiri.

Ruang lingkup kemampuan ini tidak terbatas pada apa yang Peneliti ukur saja, namun juga masih ada pengembangannya. Contoh pengembangan dalam bentuk lain adalah, kemampuan flexibility and adaptability merupakan kemampuan peserta didik untuk mampu beradaptasi pada setiap perbedaan kondisi lingkungan, bertanggung jawab, memiliki jadwal, dan efektif waktu (Rakhmawati \& Priyana, 2019).

10. Initiative and Self-Direction Skill

Tingkat kesiapan peserta didik pada indikator initiative and self direction adalah 3.26, dengan kategori siap. Peserta didik sudah mampu untuk berinisiatif dan memiliki pengarahan diri sendiri, menyusun tujuan yang akan dicapai, memiliki langkah-langkah dan mengatur strategi, mengevaluasi perencanaan, mengatur waktu pencapaian tujuan yang akan dicapai, mengusahakan perencanaan sesuai waktu yang ditentukan, mengevaluasi proses yang dilakukan, mengikuti evaluasi yang dilakukan orang lain, menyusun perencanaan baru, melaksanakan kegiatan dengan mengacu pada evaluasi prosessebelumnya.

Kemampuan berinisiatif dan mengarahkan diri akan membuat peserta didik menjadi mandiri. Kemampuan ini akan tertanam jika peserta didik dilatih (Quieng, Lim, \& Lucas, 2015), dibimbing dan dipantau (Majumdar et al., 2018) oleh orang yang lebih memahaminya. Oleh karena itu, peran guru sangat penting.

\section{Social and Cross-Cultural Skill}

Tingkat kesiapan peserta didik pada indikator ini adalah 3.19, dengan kategori cukup siap. Peserta didik cukup mampu bersosial dengan berbagai budaya, memahami waktu yang tepat melakukan suatu percakapan dan tindakan, menjaga perkataan, mendengarkan, dan menghargai pendapat, merangkai sebuah ide yang berbeda dari orang lain menjadi sebuah inovasi, bekerja sama dengan orang lain meskipun mempunyai latar belakang yang berbeda, dan menghasilkan suatu inovasi bersama.

Kemampuan ini dapat dipengaruhi oleh faktor sosial. Misalnya, penggunaan media sosial oleh peserta didik (Flory, Essers, \& Wankel, 2016). Guru dapat menggunakan media sosial tersebut sebagai alat untuk mengembangkan potensi kemampuan peserta didik ini.

\section{Productivity and Accountability Skill}

Tingkat kesiapan peserta didik pada kemampauan productivity and accountability adalah 3.10, dengan kategori cukup siap. Peserta didik cukup mampuberproduktif, akuntabel mengenali peralatan penunjang pekerjaan, menggunakan peralatan yang tepat dalam pengerjaan, mengerjakan sesuatu dengan proses yang tepat, mengidentifikasi dan melakukan pekerjaan sampai selesai, mengembangkan potensi diri, merangkai sesuatu menjadi bermanfaat, dan meyakini bahwa yang dilakukan adalah hal yang benar.

\section{Leadership and Responsibility Skill}

Tingkat kesiapan peserta didik pada indikator leadership and responsibility adalah 3.95, dengan kategori siap. Peserta didik sudah mampu untuk memimpin dan bertanggungjawabdi lingkungan sekolah, mampu mengatur anggota kelompok, dan 
mengajak anggota kelompok untuk bekerja dengan disiplin.

Kepemimpinan adalah kemampuan yang harus dimiliki oleh setiap orang, dengan asumsi bahwa setiap orang memiliki kesempatan untuk memimpin sebuah kelompok. Sementara itu, tanggung jawab harus dimiliki oleh seorang pemimpin. Kepemimpinan dan tanggung jawab mengarah pada perubahan dimasa yang akan datang (Einzig, 2017). Untuk menjadi pemimpin, seseorang harus dapat memimpin dirinya sendiri, agar menghindari sifat egois (Shek \& Leung, 2016).

Penelitian yang Peneliti lakukan ini adalah dasar untuk pengembangan pendidikan kedepannya. Data hasil penelitian dapat menjadi landasan untuk penelitian lain. Sementara, instrumen yang kami kembangkan (JRZ.IR4.0) dapat digunakan untuk mengukur kesiapan peserta didik di sekolah menengah lainnya, dengan beberapa penyesuaian. Penelitian ini menunjang banyak penelitian yang pernah dilakukan.

\section{KESIMPULAN}

Penting bagi peserta didik untuk dapat menguasai perkembangan zaman pada usianya, seperti ilmu pengetahuan dan teknologi, agar mampu bersaing secara global dengan basis informasi di masa Revolusi Industri 4.0. persoalan ini menjadi tanggung jawab guru untuk mengarahkan pembelajaran untuk kesiapan peserta didik menghadapi masa Revolusi Indsutri 4.0, tanggung jawab sekolah untuk peka terhadap perubahan kebutuhan sekolah dan lulusan sekolah tersebut dengan melakukan berbagai analisis dan pengukuran.

Berdasarkan hasil penelitian, diketahui bahwa kondisi peserta didik di SMA Negeri 8 Padang masih pada level cukup siap menghadapi masa Revolusi Industri 4.0. Hasil pengukuran Peneliti dapat menjadi landasan untuk mengarahkan tujuan pendidikan di SMA Negeri 8 Padang khususnya, dan sekolah lainnya secara umum.

\section{DAFTAR PUSTAKA}

Abdelrazeq, A., Janssen, D., Tummel, C., Richert, A. S., \& Jeschke, S. (2016). Teacher 4.0: Requirements of The Teacher of The Future in Context of The Fourth
Industrial Revolution. In Conference Proceedings of the 9th International Conference of Education, Research and Innovation, Seville, Spain (pp. 82218226).

Ahn, S., \& Chae, K. (2016). Correlation Analysis on ICT Literacy Level and Difference of Habit to Use ICT. Journal of The Korean Association of Information Education, 20(3), 303-312.

Anggraini, H. (2019). Penguatan Sikap Komitmen Siswa terhadap Integrasi Nasional. In Forum Ilmu Sosial (Vol. 46, pp. 28-41).

Arikunto, S. (2010). Prosedur Penelitian, Suatu Pendekatan Praktik. Jakarta: Rineka Cipta.

Darmadi, H. (2016). Tugas, Peran, Kompetensi, dan Tanggung Jawab Menjadi Guru Profesional. Edukasi: Jurnal Pendidikan, 13(2), 161-174.

Einzig, H. (2017). The Future of Coaching: Vision, Leadership and Responsibility in a Transforming World. Routledge.

Fauziah, G., \& Lestari, A. W. (2018). Pembudayaan Gerakan Literasi Informasi Siswa Tingkat Sekolah Dasar di Tanggerang Selatan. Edulib, 8(2), 167179.

Flory, M., Essers, J., \& Wankel, C. (2016). Developing Cross-Cultural Managerial Skills Through Social Media. Journal of Organizational Change Management.

Gralewski, J., \& Karwowski, M. (2019). Are Teachers' Ratings of Students' Creativity Related to Students' Divergent Thinking? A Meta-analysis. Thinking Skills and Creativity, 33, 100583. https://doi.org/https://doi.org/10.1016/j.tsc. 2019.100583

Harahap, A. R., \& Harahap, M. S. (2018). Efektifitas Penggunaan Constructivism Approach Terhadap Kemampuan Komunikasi Matematis Siswa Kelas XI SMA Negeri 7 Padang Sidimpuan. MathEdu (Mathematic Education Journal), 1(2), 1-6.

Hidayatullah, M. S., \& Zwagery, R. V. (2018). Efektifitas Pelatihan Goal Setting Untuk Meningkatkan Komitmen Tugas pada Siswa SMPN 1 Martapura Timur. Jurnal Ecopsy, 5(1), 16-21.

Holmes, N. G., Wieman, C. E., \& Bonn, D. A. (2015). Teaching Critical Thinking. Proceedings of the National Academy of 
Sciences, 112(36), 11199-11204.

Huber, C. R., \& Kuncel, N. R. (2016). Does College Teach Critical Thinking? A MetaAnalysis. Review of Educational Research, 86(2), 431-468.

Laisema, S. (2018). Development of Collaborative Blended Learning Activity on Mobile Learning to Enhance Undergraduate Students' Collaboration Skills. Veridian E-Journal, Silpakorn University (Humanities, Social Sciences and Arts), 11(4), 682-699.

Lestari, M. D. (2016). Analisis Kemampuan Guru Biologi SMA di Kota Semarang Dalam Membuat Rencana Pelaksanaan Pembelajaran (RPP) Berdasarkan Kurikulum 2013. Universitas Negeri Semarang.

Lewa, I. W. L., Susanto, H., \& Marwoto, P. (2018). Implementasi Model Pembelajaran Inkuiri Terbimbing pada Kemampuan Pemecahan Masalah Fisika dan Kemampuan Komunikasi Siswa SMP. UPEJ Unnes Physics Education Journal, $7(2), 44-51$.

Lie, A., \& Harjanto, I. (2018). Seberkas Cahaya di Tanah Harapan.

Magen-Nagar, N., Shachar, H., \& Argaman, O. (2019). Changing the Learning Environment: Teachers and Students' Collaboration in Creating Digital Games. Journal of Information Technology Education: Innovations in Practice, 18, 61-85.

Majumdar, R., Yang, Y. Y., Li, H., Akcapinar, G., Flanagan, B., \& Ogata, H. (2018). GOAL: A System to Support Learner's Acquisition of Self Direction Skills. AsiaPacific Society for Computers in Education (APSCE).

Mardhiyah, K. Z., \& Indianti, W. (2018). Mediasi Konsep Diri Akademik Dalam Peran Regulasi Diri Belajar Terhadap Komitmen Kepada Pilihan Karir Siswa SMA. Jurnal Psikologi Insight, 2(2), 6783.

Matteucci, M. C. (2016). Responsibility for School Outcomes: Teachers, Students, and Parents Point of View. In EDULEARN16 Proceedings (pp. 8981-8988). IATED.

Murti, D. P., \& Winoto, Y. (2018). Hubungan Antara Kemampuan Literasi Informasi dengan Prestasi Belajar Siswa SMAN 1 Cibinong Kabupaten Bogor. BIBLIOTIKA:
Jurnal Kajian Perpustakaan Dan Informasi, 2(1), 1-5.

Nilawati, N., Duskri, M., \& Sari, N. T. (2019). Penggunaan Model Pembelajaran Brain Based Learning untuk Meningkatkan Kemampuan Komunikasi Siswa MTs. MaPan: Jurnal Matematika Dan Pembelajaran, 7(1), 85-98.

Ningsih, K. I. (2018). Library Class: Model Pembelajaran Literasi Informasi Tingkat Sekolah Dasar (Studi Kasus SD Madania). Jurnal Perpustakaan Pertanian, 27(2), 5158.

Nugroho, E. (2018). Prinsip-prinsip Menyusun Kuesioner. Universitas Brawijaya Press.

Palunga, R., \& Marzuki, M. (2017). Peran Guru dalam Pengembangan Karakter Peserta DIdik di Sekolah Menengah Pertama Negeri 2 Depok Sleman. Jurnal Pendidikan Karakter, 7(1).

Quieng, M. C., Lim, P. P., \& Lucas, M. R. D. (2015). 21st Century-Based Soft Skills: Spotlight on Non-Cognitive Skills in a Cognitive-Laden Dentistry Program. European Journal of Contemporary Education, 11(1), 72-81.

Rakhmawati, D. M., \& Priyana, J. (2019). A Study on 21st Century Skills Integration in the English Textbook for Senior High School. JEES (Journal of English Educators Society), 4(1), 9-16.

Shek, D. T. L., \& Leung, H. (2016). Developing Self-Leadership and Responsibility and Moving Away From Egocentrism. International Journal on Disability and Human Development, 15(2), 157-164.

Siddiq, F., Gochyyev, P., \& Wilson, M. (2017). Learning in Digital Networks-ICT literacy: A novel assessment of students' 21 st century skills. Computers \& Education, 109, 11-37.

Siddiq, F., \& Scherer, R. (2019). Is There a Gender Gap? A Meta-analysis of The Gender Differences in Students' ICT Literacy. Educational Research Review, 27, 205-217.

So, K., \& Hu, Y. (2019). Understanding Creativity in an Asian School Context: Korean Teachers' Perspectives. Thinking Skills and Creativity, 33, 100573. https://doi.org/https://doi.org/10.1016/j.tsc. 2019.100573

Sugandi, A. I., \& Bernard, M. (2018). Penerapan Pendekatan Kontekstual Terhadap 
Kemampuan Pemahaman Dan Komunikasi Matematis Siswa SMP. Jurnal Analisa, $4(1), 16-23$.

Sweet, L. (2019). Using a Learning and Skill Acquisition Plan to Develop a Learner's Knowledge, Skills, and Professional Practice Attitudes. Ultrasound in Medicine and Biology, 45, S31.

Syafril, M. P., \& Zen, Z. (2019). Dasar-Dasar Ilmu Pendidikan. Depok: Prenada Media.

Tomlinson, C. A. (2001). How to Differentiate Instruction in Mixed-Ability Classrooms (2nd). United States: ASCD.

Wu, X., Zhu, X., Wu, G.-Q., \& Ding, W. (2013). Data mining with big data. IEEE Transactions on Knowledge and Data Engineering, 26(1), 97-107.

Wurianto, A. B. (2019). Literasi Bahasa dan Sastra Indonesia Menuju Kewirausahaan Profesi di Era Revolusi Industri 4.0 dan Society 5.0 (Peluang dan Tantangan). In Prosiding Seminar Nasional Bahasa dan
Sastra Indonesia (SENASBASA) (Vol. 1).

Zelfiah, Z. (2018). Pengaruh Kompetensi Individu Terhadap Literasi Media Internet di Kalangan Siswa SMA IT Wahdah Islamiyah. Al-Munzir, 10(2), 320-340.

Zentner, A. (2016). Communication Skill Development: an Antecedent to Leadership Effectiveness. Available at SSRN 2851790.

Zikopoulos, P., \& Eaton, C. (2011). Understanding Big Data: Analytics for Enterprise Class Hadoop and Streaming Data. McGraw-Hill Osborne Media.

Zioga, I., Harrison, P. M. C., Pearce, M. T., Bhattacharya, J., \& Luft, C. D. B. (2019). From Learning to Creativity: Identifying The Behavioural and Neural Correlates of Learning to Predict Human Judgements of Musical Creativity. NeuroImage, 116311. https://doi.org/https://doi.org/10.1016/j.neu roimage.2019.116311 